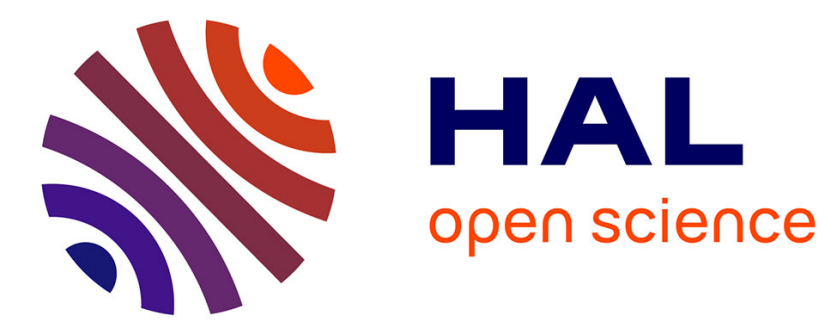

\title{
Elastostatic Modelling of a Wooden Parallel Robot
} Lila Kaci, Clément Boudaud, Sébastien Briot, Philippe Martinet

\section{To cite this version:}

Lila Kaci, Clément Boudaud, Sébastien Briot, Philippe Martinet. Elastostatic Modelling of a Wooden Parallel Robot. 7th IFToMM International Workshop on Computational Kinematics (CK2017), May 2017, Poitiers, France. hal-01479412

\section{HAL Id: hal-01479412 \\ https://hal.science/hal-01479412}

Submitted on 24 Jun 2019

HAL is a multi-disciplinary open access archive for the deposit and dissemination of scientific research documents, whether they are published or not. The documents may come from teaching and research institutions in France or abroad, or from public or private research centers.
L'archive ouverte pluridisciplinaire HAL, est destinée au dépôt et à la diffusion de documents scientifiques de niveau recherche, publiés ou non, émanant des établissements d'enseignement et de recherche français ou étrangers, des laboratoires publics ou privés. 


\title{
Elastostatic Modelling of a Wooden Parallel Robot
}

\author{
L. Kaci $^{1,2}$, C. Boudaud ${ }^{3}$, S. Briot ${ }^{1}$ and P. Martinet ${ }^{1,2}$ \\ ${ }^{1}$ Laboratoire des Sciences du Numérique de Nantes (LS2N), \\ UMR CNRS 6004, Nantes, France. ${ }^{2}$ École Centrale de Nantes, France \\ e-mail: \{Lila.Kaci,Sebastien.Briot,Philippe.Martinet $\} @ i r c c y n . e c-n a n t e s . f r$ \\ ${ }^{3}$ LIMBHA, Goupe École Supérieure du Bois, Nantes, France \\ e-mail: clement.boudaud@ecoledubois.fr
}

\begin{abstract}
Eco-design of industrial robots is a field of research which has been rarely explored in the past. In order to considerably decrease the environmental impact of robot during the design phase, metal or carbon composite parts can be replaced by bio-sourced materials, such as wood. Indeed, wood has interesting mechanical properties, but its performance / dimensions will vary with the atmospheric conditions / external solicitations and with the conditions in which trees have grown. In order to be able to design a stiff industrial robot, robust design approaches must be used. These approaches must be fed with elastostatic models that are able to predict the variability in the robot deformations due to the variability of the wood mechanical properties.

In this paper, we develop an elastostatic model for a wooden parallel robot which is able to cope with the variations of the wood mechanical properties. The prediction of this model in terms of deformations are compared with experimental measurements made on a wooden parallel robot mockup. Results show that there is a good correlation between the measurement displacements and the computed ones.
\end{abstract}

Key words: Eco-design, parallel robot, elastostatic model, wood

\section{Introduction}

The Climate Change Mitigation (CCM) has become a priority in the world, as shown during the COP21. It becomes urgent to decrease the Environmental Impact (EI) of the human activities. Robotics, which takes an increasing place in our everyday life, must also be part of this effort.

A recent study [2] shows that, contrary to what could be imagined, a large percentage (around $50 \%$ ) of the EI during the entire robot life is due to the use of metallic materials (steel or aluminum, even if they are recycled) for the design of their links. The percentage is even worth if carbon composites are used. The rest of the EI is globally due to the robot energy consumption during use.

A method to reduce EI of robot design, that is rarely used, is to replace the polluting metals and carbon composites with bio-sourced materials (BSM) that have a little (even no) EI [16, 12]. Moreover, BSM have good stiffness performance, and their quantity is only limited by their growing time [10]. In this work, developped in the scope of the French project RobEcolo [3], we are interested in using wood instead of metals to design the robot links.

Using wood in machines is not a new idea. For instance, it is used in chassis of cars [1]. It found also applications in the design of buildings due to its stiffness and low cost [10]. It is also used in Robotics for the design of mock-ups and proof- 
of-concept prototypes $[15,14]$. However, a detailed study of these works shows that wood is never used in critical parts ensuring accuracy. Indeed, the wood performance / dimensions will vary with the atmospheric conditions / external solicitations and with the conditions they have grown [10, 17]; thus, new robot design issues appear: How to be sure that an industrial robot made with wood can be accurate and stiff even if wood properties vary?

A first attempt to introduce wood in industrial robot design was presented in [12]. The results showed that the approach was valid enough to compete with usual materials. However, this study did not deal with the aforementioned issues.

Indeed, the accuracy issue can be treated through proper control approaches: external sensors combined with proper controllers can be used to accurately control the platform pose [4]. Regarding the robot stiffness, we believe that this issue can be handled through robust design approaches [18]. However, these design approaches must be fed with stiffness models which are able to predict the variability of the robot deformations due to the variability in the material properties.

In this vein, the present paper aims at proposing an elastostic model of a wooden parallel robot being able to predict the deformations and their variability.

\section{Mechanical Properties of Wood}

Wood is an organic product structure of infinite variation of detail and design. It is on this account that no two woods are alike: in reality no two specimens from the same log are identical [11]. Several studies giving the mechanical properties (e.g. Young's modulus, Poisson's ratios) for different pieces of wood can be found in the literature $[9,10]$. The properties are defined by repeated tests, that provide mean values and rarely the standard deviation (it is known that the coefficient of variation can reach up to $30 \%$ for some characteristics [10]).

We are investigating the wood in the design of industrial parallel robots, hence it is necessary to know the mechanical properties of the wood to define the elastic deformation of the robot due to the loads applied on it. However wood is subject to a scale effect: impact of singularities (e.g. knots, direction of grain) are linked to the size of the pieces of wood. Therefore new tests have to be performed to define the mechanical properties corresponding to the dimension of the robot links. Indeed, values given in $[9,10]$ are usually obtained for beams of large dimensions unlike the links of our robot which will be much smaller. Moreover, unlike usual material used in robot design, wood is an orthotropic material. The three different directions are longitudinal $L$, radial $R$, and tangential $T$. According to the theory of elasticity, the wood is parameterizes by three Young's moduli $\left(E_{L}, E_{R}\right.$ and $\left.E_{T}\right)$, six Poisson's ratios $\left(v_{L R}, v_{L T}, v_{R T}, v_{R L}, v_{T L}, v_{T R}\right)$ and three moduli of rigidity $\left(G_{L R}, G_{L T}, G_{R T}\right)$.

The links of parallel robots have cross-sections with smaller dimensions than the link lengths [13], and can be modeled according to the beam theory (Euler-Bernoulli model). For this reason, in this work only the longitudinal Young's modulus $E_{L}$ and Poisson's ratio $v=\frac{\left(v_{L R}+v_{L L}\right)}{2}$ are necessary.

In order to decrease the dimensional variability of wood due to humidity, we decided to design our links with a novel type of acetylated wood $[17,7]$ named 


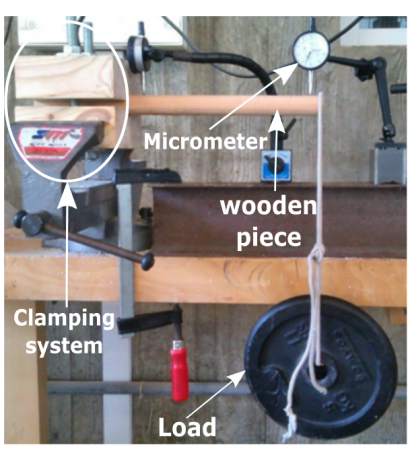

(a) Experimental setup

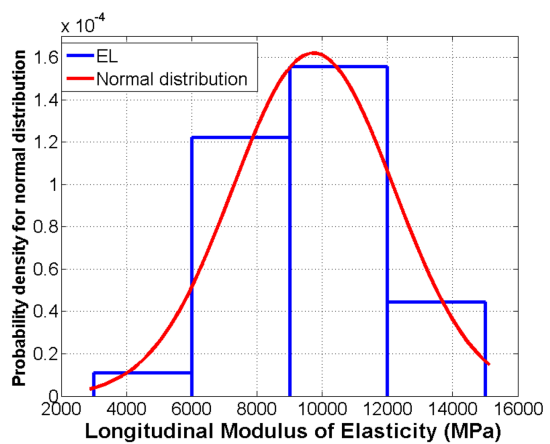

(b) Longitudinal Young's modulus

Fig. 1 Experimental setup to define the mechanical properties of Accoya Pine

Accoya Pine. This wood is known to have many advantages over raw wood species in terms of durability and dimensional stability. This choice implied that we had to made mechanical tests because no data are provided in literature for this new type of wood. Hence, to define the Young's modulus $E_{L}$ of Accoya Pine, bending tests were made (testing for the Poisson's ratio is not useful, as it has a relatively small impact on the bending strain [9]). Thirty specimens are used, the dimensions of the specimens are the same as the dimensions of a standard link of the robot we plan to build (length of $30 \mathrm{~cm}$ and square section of $3 \mathrm{~cm} \times 3 \mathrm{~cm}$ ).

Cantilever tests were performed using loads of $1 \mathrm{~kg}, 2 \mathrm{~kg}$ and $5 \mathrm{~kg}$ (Fig. 1(a)) and the measure of the deflection is used to compute $E_{L}$ (the computation was inspired by the usual EN 408 standard). It is very important to mention that the preconditioning of the specimens was made at a temperature of 20 Celsius deg. and at a relative humidity of $65 \%$, which for this specific acetylated wood implies a moisture content of $3.1 \%$.

As shown on Fig. 1(b), we obtain a variable Young's modulus which follows a normal distribution with mean value equal to $9732 \mathrm{MPa}$, standard deviation of $2462 \mathrm{MPa}$. This data will be used as input of the model presented in the next section.

\section{Estimation of the robot elastic displacement}

\subsection{Stiffness modeling of a five-bar mechanism}

The planar five-bar mechanism (Fig. 2(a)) is a two degrees-of-freedom (dof) parallel robot able to achieve two translations in the plane $\left(\mathbf{x}_{0} O \mathbf{y}_{0}\right)$. The end-effector is located at point $C$.

The analytical stiffness model presented in this section is based on matrix structural analysis method. This model was used in [6] in order to calculate the displacement of the end-effector of a parallel robot, under some external loadings.

The five-bar mechanism under study is modelled with four 3D flexible beams, each beam having two nodes at their extremity corresponding of the characteristic 


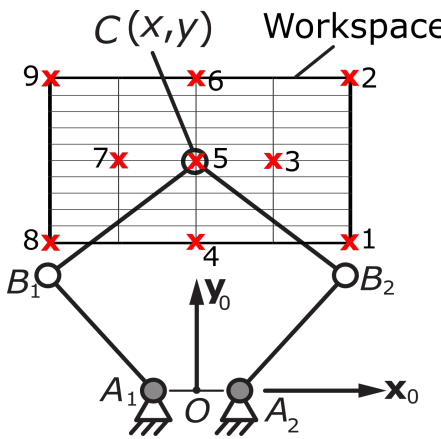

(a) Schematic of the five-bar mechanism (actuators in gray)

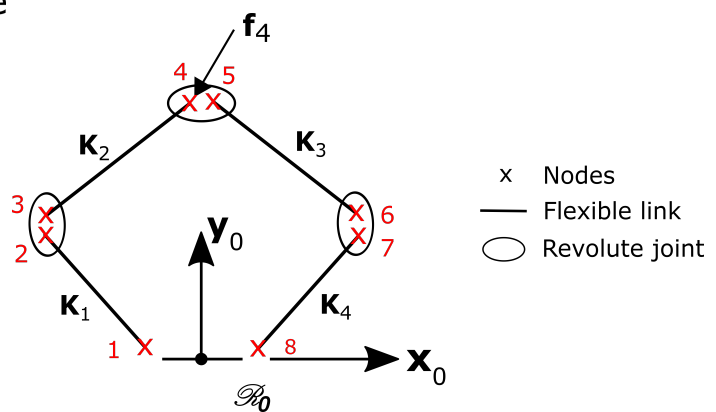

(b) Beam representation

Fig. 2 The five-bar mechanism and its stiffness model

points (Fig. 2(b)). Nodes 1 and 8 are clampled onto the groud while some kinematic constraint relations will be imposed to the other nodes in order to parameterize the free rotations of the passive revolute joints.

The stiffness matrix ${ }^{i} \mathbf{K}^{i}$ associated with the beam $i(i=1$ to 4 (Fig. 2(b))) and expressed in its local frame $\mathscr{R}_{i}$ is a 12-dimensional constant square symmetric matrix and depends on the geometrical and mechanical parameters [8].

${ }^{i} \mathbf{K}^{i}$ can be expressed in the base frame of the mechanism $\mathscr{R}_{0}$ by using the following relation:

$$
{ }^{0} \mathbf{K}^{i}=\mathbf{T}^{-1}{ }^{i} \mathbf{K}^{i} \mathbf{T} \quad \text { with: } \quad \mathbf{T}=\left[\begin{array}{llll}
\mathbf{R} & \mathbf{0}_{3} & \mathbf{0}_{3} & \mathbf{0}_{3} \\
\mathbf{0}_{3} & \mathbf{R} & \mathbf{0}_{3} & \mathbf{0}_{3} \\
\mathbf{0}_{3} & \mathbf{0}_{3} & \mathbf{R} & \mathbf{0}_{3} \\
\mathbf{0}_{3} & \mathbf{0}_{3} & \mathbf{0}_{3} & \mathbf{R}
\end{array}\right]
$$

where $\mathbf{R}$ is the rotation matrix from the local frame $\mathscr{R}_{i}$ to the base frame $\mathscr{R}_{0}$, and $\mathbf{0}_{3}$ is a $(3 \times 3)$ zero matrix. ${ }^{0} \mathbf{K}^{i}$ can be decomposed into the four following $(6 \times 6)$ sub-matrices:

$$
{ }^{0} \mathbf{K}^{i}=\left[\begin{array}{ll}
{ }^{0} \mathbf{K}_{11}^{i} & { }^{0} \mathbf{K}_{12}^{i} \\
{ }^{0} \mathbf{K}_{21}^{i} & { }^{0} \mathbf{K}_{22}^{i}
\end{array}\right]
$$

Stiffness assembly [8] is a technique used to define the stiffness matrix of the a whole structure. For the five-bar mechanism, all the beam stiffness matrices are assembled in the base frame according to the nodes as follows:

$$
{ }^{0} \mathbf{K}_{t}=\left[\begin{array}{cccccc}
{ }^{0} \mathbf{K}_{22}^{1} & \mathbf{0}_{6} & \mathbf{0}_{6} & \mathbf{0}_{6} & \mathbf{0}_{6} & \mathbf{0}_{6} \\
\mathbf{0}_{6} & { }^{0} \mathbf{K}_{11}^{2} & { }^{0} \mathbf{K}_{12}^{2} & \mathbf{0}_{6} & \mathbf{0}_{6} & \mathbf{0}_{6} \\
\mathbf{0}_{6} & { }^{0} \mathbf{K}_{21}^{2} & { }^{0} \mathbf{K}_{22}^{2} & \mathbf{0}_{6} & \mathbf{0}_{6} & \mathbf{0}_{6} \\
\mathbf{0}_{6} & \mathbf{0}_{6} & \mathbf{0}_{6}^{0} & \mathbf{K}_{11}^{3} & { }^{0} \mathbf{K}_{12}^{3} & \mathbf{0}_{6} \\
\mathbf{0}_{6} & \mathbf{0}_{6} & \mathbf{0}_{6} & { }^{0} \mathbf{K}_{21}^{3} & { }^{0} \mathbf{K}_{22}^{3} & \mathbf{0}_{6} \\
\mathbf{0}_{6} & \mathbf{0}_{6} & \mathbf{0}_{6} & \mathbf{0}_{6} & \mathbf{0}_{6} & { }^{0} \mathbf{K}_{11}^{4}
\end{array}\right]_{(36,36)}
$$


The structure of the mechanism is composed by three passive revolute joints, the characteristics of a revolute joint is that all movements of two adjacent nodes are the same except the rotation around joint axis. Those joint properties can be described by using the kinematic relation between two nodal displacements [6].

Assembling all these kinematic relations into a unique expression gives:

$$
{ }^{0} \mathbf{A}_{t} \Delta \mathbf{x}_{t}=\mathbf{0}_{(36,1)}
$$

where, in our problem, $\mathbf{A}_{t}$ is of dimension $(15 \times 36)$ and $\Delta \mathbf{x}_{t}=\left[\Delta \mathbf{x}_{1}^{T}, \Delta \mathbf{x}_{2}^{T}, \ldots, \Delta \mathbf{x}_{7}^{T}\right]^{T}$ is the vector gathering all the nodal displacement $\Delta \mathbf{x}_{i}$ with $i=1,2, \ldots, 7$.

In the same way we defined $\Delta \mathbf{x}_{t}$, the corresponding vector that gathers all the nodal wrenches is given by $\mathbf{f}_{t}=\left[\mathbf{f}_{1}^{T}, \mathbf{f}_{2}^{T}, \ldots, \mathbf{f}_{7}^{T}\right]^{T}$, where $\mathbf{f}_{j}$ is the wrench applied at node $j$. Taking into account the constraint expressed in equations (4), the displacement of the structure can be obtained using the stiffness relation (relation wrench/displacement) [8]:

$$
\begin{gathered}
\mathbf{K}_{G} \Delta \mathbf{x}_{G}=\mathbf{f}_{G} \\
\text { where: } \quad \mathbf{K}_{G}=\left[\begin{array}{cc}
{ }^{0} \mathbf{K}_{t} & \mathbf{A}_{t}^{T} \\
\mathbf{A}_{t} & \mathbf{0}_{15}
\end{array}\right]_{(51,51)}, \Delta \mathbf{x}_{G}=\left[\begin{array}{c}
\Delta \mathbf{x}_{t} \\
\boldsymbol{\lambda}_{t}
\end{array}\right]_{(51,1)}, \text { and } \mathbf{f}_{G}=\left[\begin{array}{c}
\mathbf{f}_{t} \\
\mathbf{0}_{15}
\end{array}\right]_{(51,1)}
\end{gathered}
$$

$\boldsymbol{\lambda}_{t}$ is the Lagrange multipliers vector necessary to take into account the kinematic constraints. The displacement is calculated as follows:

$$
\Delta \mathbf{x}_{G}=\mathbf{K}_{G}^{-1} \mathbf{f}_{G}
$$

from which the nodal displacement $\Delta \mathbf{x}_{t}$ can be extracted.

\subsection{Predictive model for the wooden robot deformation}

At this step, we have introduced the stiffness model of the five-bar mechanism taking into account that the Young's modulus and Poisson's ratio are known. However the experimental results described in section 2 showed how important is the variability of the mechanical properties of the wood. Monte Carlo method [5] can be used to solve any problem having random variables as inputs. The main purpose of this model is to study the influence of the variation of the mechanical properties of the wooden links onto the robot deformation. As robot stiffness depends on its configuration, the study of the displacement in different configurations of the robot is necessary. Hence, we decided to test the robot properties in the workspace which is discretized by the grid shown in Fig. 2(a). For each point of the grid, the method is performed as follows:

1. For each link of the robot, a value of Young's modulus is randomly generated based on the normal distribution identified in section 2 .

2. External wrenches are applied on the end-effector. Then the end-effector displacement is obtained through relation (5).

3. The previous two steps are repeated $n=40000$ times which ensure the stability of the results (identical mean value at $0.1 \mu \mathrm{m}$ ). 


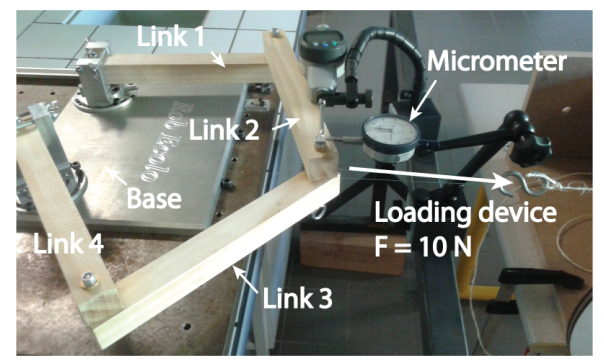

Fig. 3 Experimental setup

4. Finally, the mean, standard deviation, minimum and maximum values for the 40000 values of the displacements are calculated.

5. The process is then repeated for the other points on the grid.

This method is applied on a case study in the next section. A MATLAB code was written to compute the robot displacement using the modeling procedure presented in section 3.1. The computation of all displacements took around $35 \mathrm{sec}$. per robot configuration (for a Pentium $42.70 \mathrm{GHz}, 16 \mathrm{~GB}$ of RAM).

\section{Case study}

\subsection{Description of wooden five-bar mechanism mockup}

To validate the model proposed, a wooden five-bar mechanism mockup was developed (Fig. 3). The mockup is composed of four identical links (length of $28 \mathrm{~cm}$ and square cross section of $3 \mathrm{~cm} \times 3 \mathrm{~cm}$ ) made of Accoya Pine wood connected with three passive revolute joints. The distance between the fixed axes on the base is equal to $27 \mathrm{~cm}$.

\subsection{Experiments}

The experimental measuring setup is made of two micrometers of $0.01 \mathrm{~mm}$ resolution as presented in Fig. 3. A force of $10 \mathrm{~N}$ acting along $\mathbf{x}$ and $\mathbf{y}$ axis respectively is applied on the end-effector, and the resulting displacements at the end-effector along $\mathbf{x}, \mathbf{y}$ are measured. Tests were carried out for the nine configurations of the robot shown in Fig. 2(a). For a given configuration the experiment is repeated 10 times. Then all the experimental results are compared to the results obtained with a numerical analysis.

The results are summarized in Fig. 4. Concerning the displacements along $\mathbf{x}$-axis and $\mathbf{y}$-axis, the graphs show that the maximum and minimum experimental displacements are in the range of deformations predicted by the model. Results show that the deflections predicted by the model are in a much wider range than the experimental measurements. This was expected because numerically, 40000 values of rigidity were simulated while, experimentally, only one robot could be produced. Experimental results are globally in between the numerical limits. Nevertheless, 


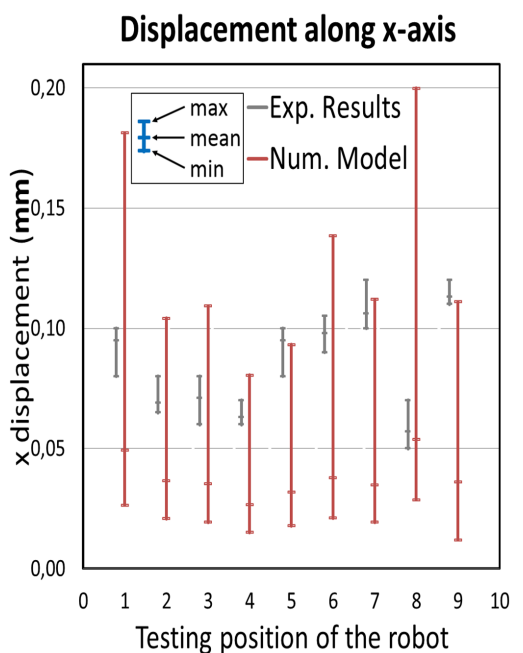

(a) Test 1

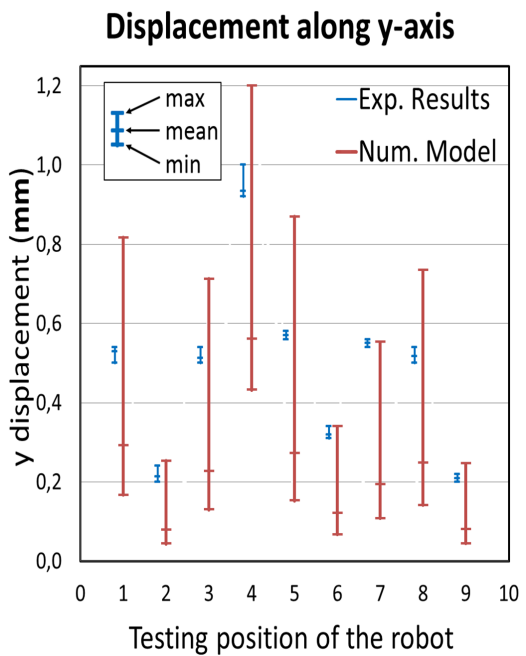

(b) Test 2

Fig. 4 Measured and simulated displacements

few predicted displacements do not match with the measurement. The theoretical and experimental results may differ because of unmodelled phenomena, like:

- The passive joint stiffness was not considered

- Viscoelasticity characteristics of the wood was not taken into account.

However, from those experiments, we can claim that the theoretical model is satisfactory and the proposed modeling procedure is efficient for predicting a realistic behavior of the wooden parallel robot.

\section{Conclusion}

Robot eco-design is a field of research in Robotics that should be deeper investigated: this could contribute to the Climate Change Mitigation.

In order to considerably decrease the environmental impact of robot during the design phase, we proposed to replace metal or carbon composite parts by biosourced materials, such as wood. Wood has interesting mechanical properties but also drawbacks: its mechanical performance encounters a large variability. In order to be able to design a stiff industrial robot, robust design approaches must be used. These approaches must be fed with elastostatic models that are able to predict the variability in the robot deformations due to the variability of the wood mechanical properties.

In this paper, we developped an elastostatic model for a wooden parallel robot which was able to cope with the variations of the wood mechanical properties. The prediction of this model in terms of deformations were compared with experimental 
measurements made on a wooden parallel robot mockup. Results have shown that there is a good correlation between the measurement displacements and the computed ones. However, differences occured between the theoretical and experimental results that may differ because of unmodelled phenomena.

Our future works will concern the refining of the proposed elastic model, the computation of the natural frequencies and the definition of a robust design methodology for wooden industrial robots.

Acknowledgements This work is supported by the French Région Pays de la Loire in the frame of the project RobEcolo (Convention No. 2015-10773).

\section{References}

1. Car manufacturer Morgan. URL http://www.morgan3wheeler.co.uk/ $\sharp$ technology

2. Fizians report. URL http://www.irccyn.ec-nantes.fr/ briot/Project_Review.html

3. Project RobEcolo. URL http://robecolo.irccyn.ec-nantes.fr/

4. Chaumette, F., Huchinson, S.: Handbook of robotics, chap. 24: Visual Servoing and Visual Tracking, pp. 563-583. Springer (2008)

5. Cools, R., Nuyens, D.: Monte Carlo and quasi-Monte Carlo methods. Springer (2014)

6. Deblaise, D., Hernot, X., Maurine, P.: A systematic analytical method for pkm stiffness matrix calculation. In: IEEE International Conference on Robotics and Automation. Orlando, Floride, USA (2006)

7. Hill, C.: Wood Modification: Chemical, Thermal and Other Processes. John Wiley \& Sons, Ltd (2006)

8. Imbert, J.: Analyse des structures par éléments finis. Editions Cépaduès (1984). In French

9. Kollmann, F., Côté Jr, W.: Ch. 7: Mechanics and rheology of wood. Springer-Verlag New York Inc

10. Kretschmann, D.: Ch. 5: Mechanical properties of Wood. Forest Products Laboratory, United States Department of Agriculture Forest Service, Madison, Wisconsin (2010)

11. Kretschmann, D.: Ch. 7: Stress Grades and Design properties for Lumber, Round Timber, and Ties. Forest Products Laboratory, United States Department of Agriculture Forest Service, Madison, Wisconsin (2010)

12. Laurent, T., Kergueme, J., Arnould, O., Dureisseix, D.: Vers un robot en bois: Première partie 168 (2010). In French

13. Merlet, J.: Parallel Robots, 2nd edn. Springer (2006)

14. Quigley, M., Asbeck, A., Ng, A.: A low-cost compliant 7-DOF robotic manipulator. In: Proceedings of the 2011 IEEE International Conference on Robotics and Automation (ICRA 2011) (2011)

15. Roennau, A., Kerscher, T., Dillmann, R.: Design and kinematics of a biologically-inspired leg for a six-legged walking machine. In: Proceedings of the 2010 3rd IEEE RAS \& EMBS International Conference on Biomedical Robotics and Biomechatronics. The University of Tokyo, Tokyo, Japan (2010)

16. Thakur, V.: Green Composites from Natural Resources. CRC Press (2013)

17. Wang, C., Piao, C.: From hydrophilicity to hydrophobicity: a critical review 43(1) (2011)

18. Wang, W., Caro, S., Bennis, F., Soto, R., Crawford, B.: Multi-objective robust optimization using a postoptimality sensitivity analysis technique: Application to a wind turbine design 137(1) (2014) 